\title{
The Quality of Life of Students in the Commune of Dangbo (Republic of Benin) in 2017
}

\author{
Gouthon Gilchrist Fabrice ${ }^{1, *}$, Bio Nigan Issiako ${ }^{1}$, Paraïso Moussiliou ${ }^{2}$, Tévoedjrè Doréana ${ }^{1}$, \\ Gouthon Polycarpe ${ }^{1}$, Ouendo Edgard-Marius ${ }^{2}$, Ahodéhou Marlyse ${ }^{1}$ \\ ${ }^{1}$ National Institute of Youth, Physical Education and Sport (INJEPS), University of Abomey-Calavi (UAC), Benin \\ ${ }^{2}$ Regional Institute of Public Health (IRSP), University of Abomey-Calavi (UAC), Benin
}

Received July 9, 2019; Revised October 7, 2019; Accepted October 17, 2019

Copyright $\odot 2019$ by authors, all rights reserved. Authors agree that this article remains permanently open access under the terms of the Creative Commons Attribution License 4.0 International License

\begin{abstract}
Children are an important part of any society. During the educational process, it is useful for them to enjoy a life of good quality in order to participate in the development of their community. Objective: This study aims to determine the quality of life of secondary school students in Dangbo in south-eastern Benin. Method: A total of 318 adolescent students (157 girls, 161 boys) from the 6th, 5th and 4th grade classes were selected according to the non-random method and the convenience technique answered a questionnaire that takes into account the five basic human needs: food, shelter, clothing, health and education. Results: A total of 159 (50.0\%), 227 (71.4\%), 318 (100.0\%), 311 (97.8\%) pupils met the criteria of good levels of educational conditions, housing, food and clothing respectively. Only one student, or $0.3 \%$ of the respondents, met the criteria for good levels of health conditions. The good quality of life resulting from the good living conditions was observed in only $122 / 318$ or $38.4 \%$ of the students surveyed. Conclusions: Since health is the weak link in the quality of life of these students, an epidemiological diagnosis is necessary to identify the modalities of effective management.
\end{abstract}

Keywords Individual Satisfaction, Adolescents, Living Conditions, Basic Needs, Benin

\section{Introduction}

Quality of life is a global individual's satisfaction with life as well as the general sense of personal well-being [1]. It takes into account the different dimensions of well-being and functional capacity studied from both an objective and subjective perspective [2]. It is necessary for everyone, especially children, to have a good quality of life for their full development in order to participate in the development of their communities. This is why these children need to be placed in an environment that is favourable to their physical, mental, psychological and intellectual development for a good quality of life.

Moreover, quality of life is influenced by the individual's perception of his or her physical, psychological, social, economic and political environment [3]. Quality of life thus covers several dimensions, some of which are qualified as objectives, such as material situation, physical health or emotional balance, social isolation, etc., while others are more subjective, such as satisfaction with one's life [4]. The evaluation of quality of life is structured around at least three dimensions, namely the physical, psychological and social domains [5].

It is important to study this concept because it allows us to describe the environment of individuals belonging to a community. This diagnosis promotes strategies to improve the living conditions of these individuals. Quality of life cannot be perceived in the same way by children and adults. For adults or parents of children, it incorporates aspects such as health, education, income, social ties, employment, housing and access to health care [6]. As a result, a child's quality of life depends on the quality of life of his or her parents. This quality of life must take into account the five basic needs of mankind: food, shelter, clothing health care and education. Children are at the heart of development, so it is necessary for them to live healthily and maintain a good quality of life. Therefore, support in the performance of the child's tasks is necessary, starting from a process of identification to the satisfaction of his or her needs for his or her full development. Therefore, these needs have an influence on the student's development with a direct impact on his or her behaviour [7]. It should be noted that children's needs and aspirations change throughout their development [2].

A child who has met these basic needs will have a good motivation. Despite the actions undertaken by the Beninese 
State and specialized organizations for the well-being of students, urgent measures are to be taken to improve their quality of life. The need to diagnose the quality of life of students in Dangbo commune would focus more on the actions to be taken. The objective of this study was to analyze the quality of life of students.

\section{Methods}

The population of Dangbo commune was estimated in 2013 at 96,426 inhabitants, 50.96\% of whom are women. In this municipality there are 19,613 households with an average size of 3.9 persons per household. Moreover, this population is young because the under 15 years represent $46.15 \%$ of the population. This young population of Dangbo poses the problem of education, health and employment in particular to the public authorities.

This descriptive, quantitative, cross-sectional study was carried out in June 2018 in two Colleges of General Education (CEG) in the municipality of Dangbo. Of all the colleges in this municipality, only two CEG gave their approvals for the conduct of the survey. In the CEG in Benin such as those in Dangbo, there are seven levels of study ranging from grade sixth to Terminale. The sixth grade corresponds to the first level of study; the fifth to the second level; the fourth to the third level and so on. The minimum sample size is 267 subjects according to the Schwartz formula with a $6 \%$ margin of error. Since there is no information on the estimated proportion of the population with the characteristic, the rate of $50 \%$ has been set.

The students met the following criteria: they had given their informed and written consent, they were regularly enrolled in one of the selected colleges for the academic year 2017-2018, and they had resided in the commune of Dangbo for at least two years. The target group consists of students selected from CEG 1 Dangbo and CEG Késsounou in the commune of Dangbo. The non-random method with the accidental sampling technique allowed 318 students to be selected on the basis of the inclusion criteria set. This questionnaire was pre-tested in a different area than the survey area (CEG 2 Akpro-Missérété).

In this work, quality of life was assessed through five sub-variables corresponding to the five basic needs (food, shelter, clothing, health care and education). To enjoy a good quality of life, the five sub-variables must be correctly met. The composite variable "quality of life" is made up of the sub-variables "food, shelter, clothing, health care and education". Individuals were therefore classified according to their responses. The sub-variables of quality of life are all dichotomous and classified as "Good" or "Bad" (right answers versus wrong answers).

The study conditions were considered good if all four major criteria were met (Interruption of studies: no; resumption of classes: no; absence from class: no and result: average) and one of the minor criteria (preschool age: 3-7 years; supply arrangements and books: yes and result: good). The level of housing conditions was considered good if the four major criteria were met (water source: soneb, lighting layout: yes; type of lighting: sbee; latrine layout in the house: yes) and one of the minor criteria (water point layout: yes; appearance of the housing materials: yes; latrine type: modern; number of people in the bedroom: 1-3 people). The level of clothing conditions was considered as good if all three major criteria were met (possession of clothing: home, khaki and sport; possession of pairs of shoes: school and home; means of acquiring clothing and shoes: parents) and one of the minor criteria (number of copies of clothing: 1 or more different types of pairs of shoes; number of pairs: 1 or more; quality of clothing and pairs of shoes worn: good or average). In relation to feeding conditions, the level was considered good if the six major criteria were met (feeding frequency: 3 or 4 times and more; feeding variation: yes; feeding variation per day: yes; satiety food consumption: always; existence of a food supply source in the college: yes; feeding source in the college: domestic seller) +1 of the 2 minor criteria (feeding schedule; food storage at home). The good level of health conditions could be observed among the respondents if they met all five major criteria (caregiver in case of illness: Doctor, illness during the school year: Never, appreciation of the health care received: Satisfactory, absence during the course due to illness: Never, appreciation of the state of health during the school year: good). For each of the above conditions, the level was considered poor if only one major criterion was not met or if all the major criteria were met and none of the minor criteria was met.

In general, quality of life is good when the five basic needs are met (education, housing, food, health care and clothing). The level is low when one of the basic needs is not met.

The quantitative data collected were processed with the IBM SPSS Statistics software (Version 20). Descriptive statistics are presented in the form of headcounts with relative frequencies.

\section{Results}

A total of 318 adolescent students (13.3 \pm 1.6 years old) aged 9 to 19 years old, 157 of whom were girls and 161 boys, formed the study sample. There were 146, 140 and 32 of them respectively in 6th, 5th and 4th grade classes. Of all the respondents, 311 (97.8\%) had a good level of study conditions. The good level of housing conditions was observed in 227 or $71.4 \%$ of respondents. Among the respondents, 159 or $50 \%$ of the respondents had good and poor feeding conditions. Of the 318 respondents, only one student had a good level of health conditions. In relation to clothing conditions, all 318 respondents were at a good 
level (Table 1). Generally speaking, on the basis of the standards set for a good quality of life taking into account the five basic needs of pupils, only 122 or $38.4 \%$ reported a good level (Table 1).

Table 1. Level of satisfaction of respondents' basic needs and quality of life $(n=318)$

\begin{tabular}{|c|c|c|}
\hline & \multicolumn{2}{|c|}{ Termes and conditions } \\
\hline Variables & $\begin{array}{c}\text { Good } \\
\mathrm{n}(\%)\end{array}$ & $\begin{array}{c}\text { Poor } \\
\mathrm{n}(\%)\end{array}$ \\
\hline Basics need & $311(97.8)$ & $7(2.2)$ \\
\hline - Instruction & $227(71.4)$ & $91(28.6)$ \\
\hline - Housing & $159(50.0)$ & $159(50.0)$ \\
\hline - Feeding & $1(0.3)$ & $317(99.7)$ \\
\hline - Health & $318(100.0)$ & $0(0.0)$ \\
\hline - Clothing & $122(38.4)$ & $196(61.6)$ \\
\hline Quality of life & &
\end{tabular}

\section{Discussion}

This study was based on the assumption that a good quality of life for students is associated with meeting their basic needs. To test this hypothesis, a research objective was set. The aim was therefore to study the quality of life of students in Dangbo commune.

The operational aspects of the quality of life components have actually determined the quality of life of these students. The protocol for determining quality of life in adults cannot be applied to children [4]. For example, aspects related to material living conditions, psychosocial risks, economic insecurity, monthly income, employment, etc. are inappropriate for assessing children's quality of life. The World Health Organization's (WHO) conception of quality of life was based on the perception of the individual's somatic, emotional and social well-being. In this study, these main criteria were highlighted through the satisfaction of the five basic needs of children. All these precautions have ensured the good quality and reliability of the results obtained.

The learning conditions of students remain a very important element in the lives of children while contributing to the development of their being. They promote their educational level. Indeed, Education is one of the main determinants of living conditions and well-being because it would provide the individual, either in the present or in the future, with the knowledge necessary for a good contribution to the development of his community. The majority of the respondents in this research had a good level of study conditions. Well-being is a great necessity for the success of students [8]. School performance associated with well-being at school is an indicator that can predict students' academic progress and even their drop-out from school [9]. The relationship between well-being in school and academic achievement can be observed according to the age of the children and the characteristics of the schools attended [10]. Study conditions are therefore necessary in order to acquire the best knowledge, attitudes and skills of every human being in a given society.

Housing conditions are above all, properties with multiple dimensions, the choice of which depends on the location [11]. For some authors, housing conditions are associated with children's health. From a psychosocial perspective, homeownership and housing satisfaction are the characteristics of housing [12]. Compared to the results of this research, the vast majority of respondents found this need to be met depending on the operational nature of the variable. As a place or environment to live, the house must be clean and safe in order not to be exposed to certain diseases and infections. Consistent with this research, satisfaction with housing conditions is a key aspect of children's quality of life.

Food is the major determinant of health in an individual's life. Man must feed himself for his survival and growth [13]. Good nutrition provides good health. Thus there is a strong link between health and nutrition. The notion of health cannot therefore be understood without food [14]. Half of the respondents met the feeding conditions on both sides with good and bad levels. The issue of students' nutrition depends on the financial conditions or food availability to parents. Those who did not meet the right feeding conditions would certainly come from families that would not always be able to meet this need for them.. Healthy eating habits contribute to goals such as good health and well-being [15]. It is necessary for consumers to consume food with knowledge of its origin, preparation and preservation methods [16]. It is therefore essential to life in the sense that it nourishes the body to ensure good health. The need for a good food choice is essential for the physical or intellectual balance of each individual and thus depends on certain factors that characterize a person such as cultural and ethnic background.). It is therefore important to make a good food choice because it has a significant impact on our health and environment [15]. Good nutrition for students would enhance their academic performance. Research in Canada has shown that learners perform better in school when they are in good nutritional health [17].

All the children deserve to be healthy regardless of gender, religion, ethnicity, etc. Being essential in the context of this study is to highlight the need for treatment that would make it possible to know if the students of the Dangbo commune have a good quality of life. The health of students is important in the process of their development. Health education will enable students to participate in their personal development and be actors in determining their own health [18]. Almost all the respondents in this research in Dangbo did not report enjoying good health conditions. The acquisition of good health is essential, even mandatory in the process of proper development and growth of a 
human body. It requires a healthy and balanced diet that contributes to growtsh and disease prevention [19]. It is the basis for quality development. Schools are an appropriate environment for achieving quality of health [120]. Health guarantees quality education. A healthy student can perform his or her personal and academic tasks with more focus and interest. In assessing the health of the given population, the socio-economic factors were found to have an impact on perceived health, disease reporting, and activity restriction [21]. It is therefore beneficial that in each school, access to a medical service should be given to prevent or reduce as much as possible the risk of illness. It is important to take all this into account to avoid the chances of diseases and deal with food insecurity that has a negative effect on children's health [22]. Health is a major determinant for the involvement or detachment of an individual with his or her environment [19] by promoting personal development.

In this study, two limitations were identified. First of all, it concerns the sample that was formed by the accidental choice technique. This technique did not allow all students to have the opportunity to become the study sample. Based on the results obtained, interpersonal communication strategies could be implemented to improve the general living conditions of students with a low quality of life. Secondly, the parents of the subjects concerned were not interviewed. The information provided by these parents would have provided more information on the quality of life of these students. Concrete actions would help to meet the five basic needs of these students. This research is one of the first of its kind and it would be very important to investigate the issue further through further studies.

\section{Conclusions}

In short, the objective of this research was to study the quality of life of students. It was undertaken on the assumption that the good quality of life is associated with the satisfaction of five basic needs. The results of this study showed that only one-third of the respondents had a good quality of life. Individual satisfaction with a student's living conditions, therefore, requires taking into account existing strategies and policies that promote a good quality of life for these adolescents. In addition, only one student was found to be in good health. It is necessary to continue the medical investigations in order to identify the health problems related to the quality of life of the students surveyed in the commune of Dangbo.

\section{Acknowledgements}

The authors are extremely grateful to all the students and directors and censors of colleges who participated in the study.

\section{REFERENCES}

[1] Seven years AL. Methodology for assessing quality of life adapted to the end of life of cancer patients. [Exercise thesis]: University of Franche-Comté, 2014

[2] Coudronnière $\mathrm{C}$, Bacro $\mathrm{F}$, Guimard $\mathrm{P}$, Florin $\mathrm{A}$. What is the concept of quality of life and well-being in children aged 5 to 11 ? Childhood, №2, 225-43, 2015.

[3] Revicki DA. Recommendations on health-related quality of life research to support labeling and promotional claims in the United States. Qual Life Res. 2000 ; 9(8): 887-900.

[4] Godefroy P, Lollivier S. Satisfaction and quality of life. Economy and Statistics, No. 469, 199-232, 2014.

[5] - Leidy NK, Revicki DA, Geneste B. Recommendations for evaluating the validity of quality of life claims for labeling and promotion. Value Health.1999 ; 2(2): 113-27.

[6] Jakubovitch S, Bouvet S. Evolution of the quality of life: rather stable or improving. INSEE. No. 35: 1-4, 2017.

[7] Park S, Holloway, SD, Arendtsz A, Bempechat J, Li J. What makes students engaged in learning? A time-use study of within- and between-individual predictors of emotional engagement in low-performing high schools, $\mathrm{J}$ youth Adolescence, Vol. 41, No. 3, 390-401, 2012.

[8] Ontario P. Promoting and supporting student well-being in Ontario, GHP, 2017.

[9] Korhonen JK. Learning difficulties, academic well-being and educational pathways among adolescent studentsSouth African: AA, Research gate, 79, 2016.

[10] Gaudonville T. The impact of quality of life on school performance and development, CNESCO, 3-78, 2017.

[11] Laferrére A, Pouliquen E, Rougerie C. Housing in France for thirty years. INSEE. Paris, 11-220, 2017.

[12] Kohen E. Housing and health of Inuit children. Health report. Vol. 6, No.11, 23-30, 2015.

[13] Leo C, Pierron JP. Think about a food ethic. ERES. No. 4, 19-24. 2017.

[14] Ferry M. Nutrition, ageing and health. National Gerontology Fund. Vol. 33, No. 134, 123-32, 2010. Available at: https://www.cairn.info/revue-gerontologie-et-societe1-201 0-3-page-123.html

[15] Bergadaà M, Urien B. The food risk perceived as a vital risk of consumption. Emergencies, adaptation and management, Rev fr gest, No. 162, 127-44, 2006.

[16] Bush Y, Married JL, Davoust B. Public health: these infected diseases imported by food, Bull Soc Pathol Exot, Vol. 101, No. 4, 343-7, 2008.

[17] Willett W, Rockstrom J. Healthy food from sustainable production: Food for a healthy planet, 2-9, 2019.

[18] Wyonch R, Sullivan A. Health and Good Education: Healthy Eating Programs in Canada, C.D. HOWE Institute Commentary No. 532. Toronto, 2019. Available: www.cdhowe.org

[19] Naton J, Bouvet F. For healthier students. EESC. Economic, 
Social and Environmental Council. Paris, 2-75, 2018.

[20] AFSSA. Health comes with food: The food guide for all. National Nutrition and Health Programme. Saint-Yrieix-la-Perche, France: PNNS, 111, 2012.

[21] Guiet-Sylvain J, Jordan D, Parayre S, Simar C, Pizon F, Berger D. Education à la santé en milieu scolaire mise en perspective historique et internationnal, Cairn info, No. 32, 105-27, 2011.

[22] Jourdan D. Can school health education contribute to the reduction of social inequalities in health?, La santé de l'homme, No. 414, 7-42, 2011.

[23] Mc Laughlin Ka, Green JG, Alegria M, Costello EJ, Gruber MJ, Samson NA et al. Food Insecurity and Mental Disorders in a National Sample of U.S adolescents, NIH-PA, Vol.51, No.12, 1-17, 2012. 